\title{
Artículos
}

\section{El sistema judicial en El Salvador}

\author{
José M. Tojeira
}

Resumen

En este artículo, el autor analiza la situación actual del sistema judicial. Considera que para construir la paz con solidez, las sociedades deben vivir gobernadas más por leyes que por personas. Pues, pese a que las circunstancias han cambiado, algunos aspectos de la situación estructural, sobre todo económica y cultural, siguen dañando enormemente a lo que debía ser la justicia legal: el fiel de la balanza equilibradora y defensora de la igual dignidad humana, que nuestras leyes reconocen. Y algo más, que se sigue perjudicando el legítimo deseo de seguridad ciudadana y la aspiración a que la convivencia se construya sobre la regulación de deberes y derechos iguales para todos, y no sobre relaciones de fuerza o dependencia.
\end{abstract}

Analizar el sistema judicial requiere siempre, y en primer lugar, contextualizarlo. Roberto Sosa, un poeta hondureño, comenzaba una poesía dedicada al sistema judicial de su país con los siguientes versos: "Entré en la casa de la justicia de mi país, y descubrí que era un nido de encantadores de serpientes". Esta descripción respondía a algo muy vivido en casi todos los países centroamericanos en los años setenta: la experiencia de que la justicia era un negocio de unos pocos, adornado de palabrería altisonante, pero destinada al final a favorecer a los fuertes y dejar a los débiles más humillados, más empobrecidos y más silenciosos. Aunque las circunstancias han cambiado, $y$ no hay duda que he- mos ido a mejor desde aquellos años setenta, algunos aspectos de la situación estructural, sobre todo económica y cultural, siguen dañando enormemente a lo que debía ser la justicia legal: el fiel de la balanza equilibradora y defensora de la igual dignidad humana, que nuestras leyes reconocen. $Y$ algo más, se sigue perjudicando el legítimo deseo de seguridad ciudadana y la aspiración a que la convivencia se construya sobre la regulación de deberes y derechos iguales para todos, y no sobre relaciones de fuerza o dependencia. Comenzaré, pues, por lo que entorpece la vida ciudadana construida desde las leyes, para recorrer después los diversos actores y contextos del mundo de la justicia legal. 
Una sociedad con injusticias estructurales graves no puede tener un sistema judicial justo. $Y$ esto por pura lógica. Pero ello no quiere decir que no debamos luchar, al mismo tiempo que buscamos mayor justicia socioeconómica, en favor de un mejor funcionamiento de la legalidad. Y digo que la injusticia estructural impide la justicia legal por una razón muy sencilla. Si la sociedad está organizada de tal manera que la riqueza producida por todos se distribuye sin equidad y sin justicia, si quienes tienen más lo consiguen, no tanto trabajando, sino aprovechándose descaradamente del trabajo de otros sin reconocer al menos un salario digno, es difícil pensar que la maquinaria de la justicia pueda superar la fuerza de la maquinaria que mantiene a la sociedad en su desigualdad. Y no sólo eso. El control que el capital ejerce sobre el funcionamiento diario de la sociedad crea también una serie de ideas, presiones y mecanismos, los cuales terminan configurando una especie de cultura de la desigualdad. Es más quien más tiene y menos el que vive en escasez de recursos. Esta cultura de la desigualdad termina fortaleciendo el poder de quienes más tienen y haciendo difícil la tarea básica a la cual aspiran las democracias, la igualdad ante la ley.

La injusticia estructural, además, no se mantiene nunca a través de leyes democráticas, sino a través del autoritarismo. Hablando de la guerra, Kant citaba la máxima de un príncipe quien, teniendo el ejército adecuado, invocaba el uso del mismo ante los problemas que se le presentaban, con la lógica de lo que llamamos hoy la razón instrumental: "Un herrero que posea tenazas no agarra el hierro candente con las propias manos" (La paz perpetua, Madrid, 1967, p. 60). La injusticia estructural, a semejanza de la guerra, utiliza frente a los problemas fuerza material, y con la misma racionalidad del que puede usar la fuerza a discreción por el hecho de tenerla. El Salvador, desde el punto de vista legal, ha vivido la tragedia de mantener una justa aspiración a una vida normada democráticamente, según estándares internacionales, conviviendo simultáneamente con regímenes autoritarios que han actuado de facto, usando el poder arbitrariamente en favor de los propios intereses, sin preocuparse por la legalidad de su actuación. De ese pasado demasiado cercano todavía nos queda una herencia pesada. Querer juzgar a la autoridad, tratar de que quienes tienen poder o dinero permanezcan tan sujetos a las leyes como cualquier ciudadano de a pie, es tan difícil como lograr que quienes manejan carros sean respetuosos con los peatones. Al final, la razón es la misma: la cultura de la ley del más fuerte.

En El Salvador, el 20 por ciento más rico recibe el 56.5 por ciento del ingreso nacional; mientras el 20 por ciento más pobre percibe el 3.4 por ciento. El 75 por ciento de la población recibe un servicio de salud público deficiente frente a un 25 por ciento que tiene acceso a estándares más o menos decentes de servicio a la misma salud. El sistema de pensiones cubre a un bajo porcentaje de la población activa. La carga impositiva de El Salvador es una de las más bajas del continente y quienes tienen un mayor acceso a la riqueza tienen amplias posibilidades de evadir impuestos. La educación está también montada de tal manera que margina y cierra posibilidades y oportunidades a una buena proporción de los jóvenes del país. La PAES ofrece un claro ejemplo de cómo los institutos públicos y rurales tienden a tener un rendimiento inferior a los privados y urbanos. Y con márgenes de diferencia demasiado altos.

Se podría decir que, de hecho, El Salvador es un país pobre y que tiene que resolver algunos de estos problemas poco a poco. Pero lo cierto es que, aun reconociendo la pobreza, los servicios sociales podrían y deberían ser mejores. Y para ello falta voluntad política. Qué duda cabe que el presupuesto gubernamental podría recortarse en áreas no productivas, desde las partidas secretas hasta los salarios, desde el derroche en fiestas, viajes y propaganda, hasta ciertos rubros del presupuesto militar. Mejorar la recolección de impuestos, especialmente en el campo de la renta, es también cuestión de decisión política. Pero la manera de funcionar, diseñada para favorecer sistemáticamente a los que más tienen, imprime una especie de inercia al subdesarrollo. Se insiste en la producción y se olvida la distribución. Se insiste en generar riqueza, pero se deja aparte la redistribución de la misma.

En este contexto, con un 50 por ciento de la población viviendo en pobreza y con un 25 por ciento más en serias dificultades para conquistar una vida sin apuros ni privaciones, la justicia queda limitada. El que tiene dinero, influencia, recursos y poder, encuentra sin dificultades el apoyo suficiente como para salir de sus problemas. Y es que la estructura organizada para que unos pocos vivan bien, a costa de la mayoría, acaba configurando un modo de proceder cultural y extralegal, que tiene más fuerza que el propio sistema de control 
y supervisión de la legalidad, que rige la convivencia. Los sistemas legales, además, al funcionar en una sociedad con tan graves diferencias, tienden a adaptarse a las valoraciones dominantes. Tener enemigos poderosos es más peligroso en países con institucionalidad débil que en donde las leyes funcionan. Y si estos enemigos potenciales ofrecen amistad, acompañada de recompensas adecuadas, la corrupción termina enseñoreándose del sistema.

La injusticia estructural, además, genera violencia. Ella misma es violenta en sí misma, pues niega no solo la igualdad de oportunidades al ciudadano, sino la dignidad de la persona y su desarrollo, así como la libertad. El hábito de la venganza, todavía tan extendido entre nosotros, muestra por un lado el mal funcionamiento de las leyes, pero sobre todo descubre la irracionalidad de una convivencia en la cual las propias estructuras socioeconómicas y culturales despojan, excluyen y condenan a una vida con frecuencia infrahumana. El alcoholismo, los suicidios, que van adquiriendo una proporción alarmante en nuestra sociedad, y los actos de violencia en el hogar y fuera de él, nos muestran los grados de frustración a los cuales puede llevar una estructuración social poco abierta a la esperanza.

En el campo que nos ocupa, la injusticia estructural limita el desarrollo legal del país y la coherencia entre nuestra legislación y la realidad. De hecho, la ley trata básicamente de establecer un marco racional de convivencia en el cual todos podamos vivir como seres humanos iguales en dignidad, gozando de respeto a nuestra libertad y autonomía, y disponiendo de los canales adecuados para realizar, a lo largo de nuestra existencia, tanto los dina-

mismos que nos impulsan a nuestra afirmación autónoma, como aquellos que nos llevan a la realización del yo en la alteridad y la solidaridad. La irracionalidad de poner la realidad al servicio de unos pocos, de excluir a las mayorías de los beneficios de la vida social, rompe el sentido último de la ley, que tiende más a garantizar derechos que a penalizar la ruptura de los mismos. La discrecionalidad de los poderosos, su arbitrariedad, tanto ante la ley como ante el prójimo, no sólo lleva a

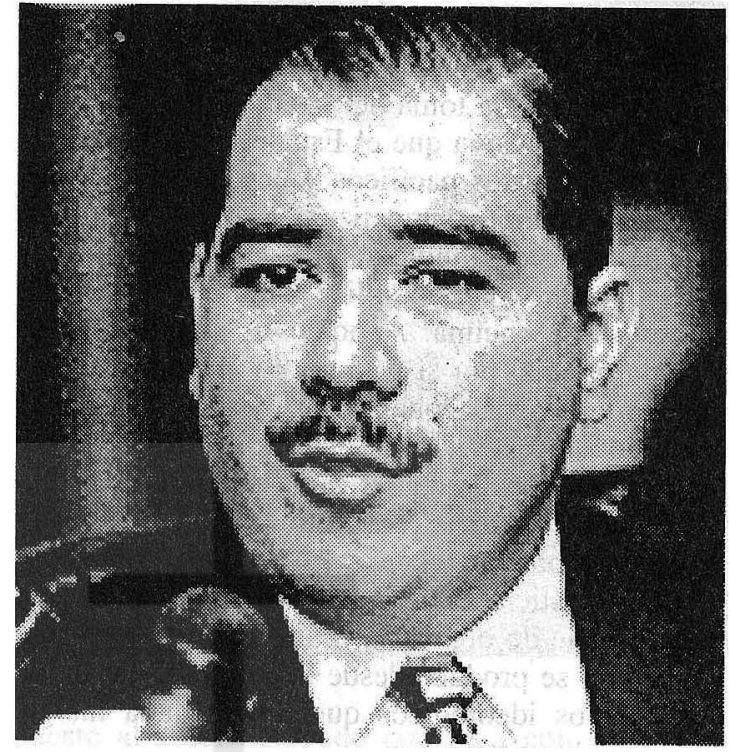

graves injusticias, sino a corromper lo que es más profundo en la humanidad y por lo que habitualmente nos definimos: la racionalidad. En el mismo libro de Kant que citábamos, el filósofo insiste en que "la fuerza perjudica inevitablemente el libre juicio de la razón" (ibídem. p. 91). La fuerza caprichosa, sistemática y puesta al servicio de unos pocos destroza cualquier principio de legalidad, impide la sana convivencia y genera nuevos y abundantes tipos de violencia. Si frente a esta realidad la justicia legal se limita a penalizar hechos reactivos, por supuesto ilegales, pero no investiga ni sanciona a quienes corrompen el sistema, se convierte automáticamente en cómplice y en promotora de la misma violencia que formalmente dice combatir.

Para nadie es un secreto que la guerra civil, que finalizó hace nueve años, tuvo en su origen esa especie de injusticia estructural que producía reclamos y descontento. Y que la respuesta violenta y represiva a los críticos del sistema provocó finalmente una espiral de violencia, en la que la barbarie se apoderó de demasiada gente. Los fraudes electorales y las masacres públicas sin que se dedujeran responsabilidades llevaron a que algunos sectores de la población iniciaran reactiva- 
mente un proceso violento, muchas veces tan injusto como el de aquellos que los provocaron, que debería llevar a la toma del poder. En la respuesta violenta y represiva que el Estado dio a los opositores, fueran estos pacíficos y partidarios del diálogo y la razón, o simpatizantes de la revolución ammada, el sistema judicial quedó como espectador pasivo y, por ende, cómplice de la brutalidad que se nos venía encima. Aunque es evidente que el sistema judicial por sí solo no hubiera podido frenar la situación, sí podemos insistir hoy en que un conjunto de instituciones dedicadas a proteger la justicia e impartirla con eficacia desarrollan la cultura de paz necesaria para que la locura de la guerra no se repita. La guerra no sólo tiene como origen la injusticia social y la pobreza, sino sobre todo la serie de ofensas a la dignidad de la persona, la cual se produce desde la cultura y desde los męcanismos ideológicos que justifican la marginačión. Y los sistemas judiciales son siempre mecanismos que o bien respaldan la dignidad de la persona o bien la hunden más en la marginación y la desigualdad. Con el agravante de mentir ostensiblemente, afirmando que están a favor de la igualdad, que la justicia es ciega y toda esa serie de aforismos que a veces no son más que palabras vacías para tapar la corrupción.

Para construir la paz con solidez, las sociedades deben vivir gobernadas más por leyes que por personas. Las constituciones expresan, dentro de esa voluntad, el marco fundamental de la vida en paz. En su calidad de instrumento jurídico, se alzan como expresión del pacto social básico para la pacífica convivencia. Por ello es importante, al hablar del sistema judicial, comenzar hablando de la Constitución y de cómo se relaciona este pacto social básico con las instituciones que deben garantizar la legalidad y la justicia. En realidad tenemos una Constitución suficientemente buena. En ella se reconoce a la persona como "el origen y el fin de la actividad del Estado" (Artículo 1), y se explicita simultáneamente la obligación estatal de asegurar el goce de "la libertad, la salud, la cultura, el bienestar económico y la justicia social". Se garantiza que quienes son pobres reciban servicio de salud gratuita, que los trabajadores tengan derecho a la indemnización proporcional al retirarse voluntariamente de sus trabajos, se reconoce el derecho de respuesta en los medios de comunicación, se dan algunas medidas contra la corrupción y el abuso, como por ejemplo la limitación del autoindulto y la autoamnistía para los funcionarios del gobierno en curso. Incluso la Constitución garantiza "la indemnización por retardación de justicia" (Artículo 17), estableciendo que tanto los funcionarios como el Estado, subsidiariamente, estarían obligados a pagarla. Pero, solo tocando el último punto, ¿cuántos salvadoreños hasta ahora han recibido una indemnización por retardación de justicia? ¿O es que acaso no existe la retardación en nuestro medio judicial? Una cosa es la ley y otra parece ser la justicia. Si en la escuela aprendimos que el sistema judicial trata de que se apliquen las leyes, la realidad parece decirnos algo en sentido contrario.

Porque en efecto, todavía pesa en nosotros la herencia de una cultura acostumbrada a mantener leyes ideales y a funcionar posteriormente con sistemas y modos que se separan de las mismas leyes y actúan paralelamente. Utilizando un análisis jurídico que contemplara rigurosamente las leyes y la jurisprudencia salvadoreñas, se podría afirmar que todas las asambleas legislativas que han legislado en El Salvador desde 1983 han violado la Constitución, al menos por omisión. El simple hecho de no legislar en aquellos puntos en los cuales la Constitución afirma que se debe legislar, y son varios, supone una violación de la misma. Pues el tiempo normal para legislar ante un mandato constitucional debería ser, como máximo, los tres años que dura el período ordinario de cada Asamblea Legislativa. Al menos eso diría la sana crítica que tanto mencionan los jueces. En ese sentido, algunos de nuestros honorables diputados llevarían ya varios trienios dedicados al noble deporte de violar la Constitución por omisión.

Este estilo de entender y practicar la legalidad es ya de por sí peligroso. Y se presta a que lo fundamental de nuestras leyes se convierta en simple motivo de chiste. Tener leyes para no cumplirlas lleva siempre a la actuación ilegal. Aunque esto es también herencia, cuyas raíces se pueden 
encontrar en la colonia española, el tiempo transcurrido debería hacernos cambiar los patrones de actuación. Ante la inoperancia y la morosidad de la sala de lo criminal mexicana en tiempos de la colonia, la sociedad funcionaba a partir de una especie de santas hermandades, la Acordada, se llamaba en particular en México, que limpiaban "caminos, campos y ciudades de vagos, maleantes y criminales... sin tolerar apelaciones a tribunales ordinarios ni inspección alguna de sus cárceles" (Guillermo Céspedes del Castillo, América hispánica, Barcelona, 1983, p. 304). Este tipo de opciones no deja de tener una cierta relación con los grupos de limpieza que hace no demasiados

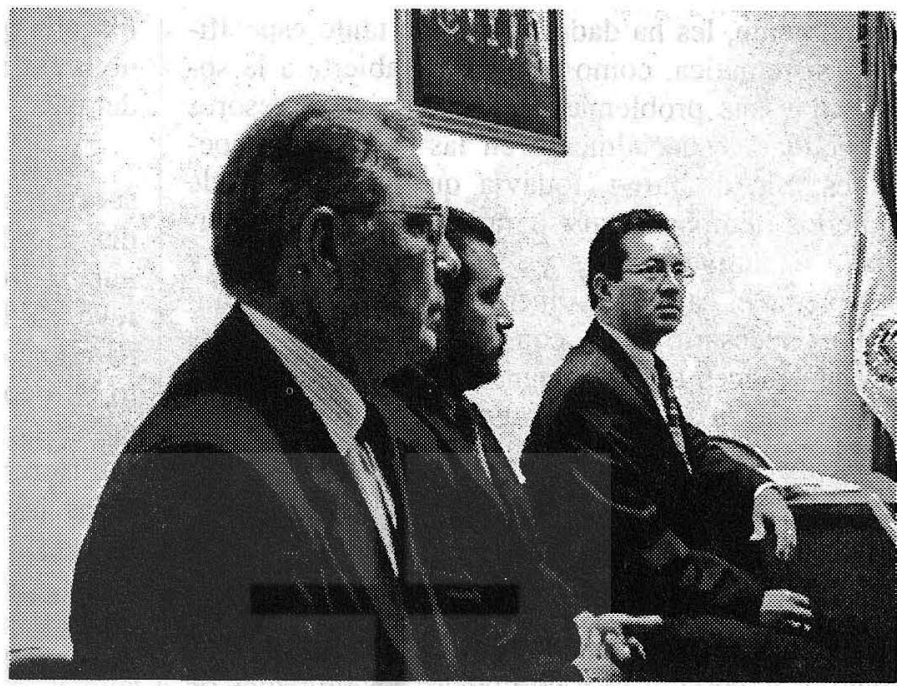
años denominábamos como escuadrones. A pesar de no tener pena de muerte en nuestra legislación, la gran proporción de homicidios en el país nos deja entender que la legislación respetuosa con la vida humana, se suple culturalmente con la apropiación individual de la imposición de una pena que cada vez consideramos más aberrante. Y la impunidad en este tipo de crímenes reafirma una vez más que el sistema judicial no tiene el monopolio de la administración de las penas.

puesto al valor agregado contrasta con la ley del impuesto sobre la renta. Mientras a una se la alaba e incluso se le aumenta el valor y el número de cotizantes, la otra muere en el sueño de la evasión sin que se pongan inspectores adecuados en número, apoyo y poder como para exigir su debido cumplimiento. Cualquier ley que de alguna manera toque intereses de quienes tienen poder $o$ influencia parece destinada al fracaso o a la burla.

Evidentemente, el problema de las leyes se despliega desde la Constitución a todo el sistema legal, ampliando el problema y agravándolo con diversos elementos. Es notable, en primer lugar, la capacidad de producir leyes que impulsan más el beneficio privado que el bien común. La ley de tenencia y portación de armas, elaborada no hace mucho tiempo, es un ejemplo de cómo los legisladores pueden olvidar la necesidad de desarmar a una sociedad violenta $y$ establecer un riguroso control del uso privado $y$ público de estos instruquienes comercializan las armas. La ley del immentos, solamente por favorecer los intereses de

La fuerza caprichosa, sistemática

y puesta al servicio de unos pocos destroza cualquier principio de legalidad, impide la sana convivencia y genera nuevos y abundantes tipos de violencia. Si frente a esta realidad la justicia legal se limita a penalizar hechos reactivos, por supuesto ilegales, pero no investiga

ni sanciona a quienes corrompen el sistema, se convierte automáticamente en cómplice y en promotora de la misma violencia que formalmente dice combatir. 
moralmente, les ha dado formación tanto específica y sistemática, como informal y abierta a la sociedad $y$ sus problemas, $y$ ha preparado asesores de calidad, especialmente en las instancias superiores. Sin embargo, todavía quedan testigos de aquellos tiempos en que para llegar a juez se estudiaba en universidades ya felizmente cerradas, y se obtenía el cargo por dinero. A pesar de los avances, es necesario decir, como el poeta, que todavía quedan jueces que oprimen la verdad, y que más de uno con su avaricia convierte "en compra y venta la justicia” (fray Luis de León). El dinero sigue aceitando resoluciones en mayor proporción de lo que desearíamos, y no sólo llegando al bolsillo de los jueces, sino muchas veces al de funcionarios de rango inferior. Difícil de evaluar, la corrupción sigue siendo como una sombra que se mueve con relativo poco control y con pocas posibilidades de ser enfrentada. Porque incluso al ciudadano que tenga indicios para denunciarla se le pide con frecuencia que aporte las pruebas, cuando éstas en realidad deben ser investigadas y elaboradas por los operadores del sistema y no por particulares. En la Corte Suprema de Justicia todavía quedan, aunque pocos, magistrados que han llegado a la misma pese a denuncias de fraude procesal o a relaciones profesionales con grupos de delincuentes, que pueden hacer temer lo peor. Y todavía se estila en algunos la petición a sus asesores de adaptar la ley a la decisión tomada de antemano, en vez de trabajar los problemas desde el apego básico a la ley. Aunque se camina, quedan rémoras del pasado.

La Fiscalía General de la República, débil, poco preparada, demasiado dependiente de los nombramientos políticos y de las presiones económicas, ha adquirido en el sistema, antes de tiempo, el monopolio de la acción penal. Indudablemente, son demasiados los casos que han demostrado la ineficacia de este cuerpo frente a la responsabilidad que se le ha dado. El caso jesuitas, con toda la serie de manipulaciones reñidas con la legalidad, medidas prácticamente fraudulentas, lentitudes e incumplimientos de los plazos que marca le ley, no es más que un pequeño ejemplo. La FEDEFUT, Katya Miranda, el caso de los furgones robados son parte de un interminable mal accionar en el cual se juntan la mala preparación, la incapacidad para investigar y el miedo a los poderosos. Incluso los jueces se han visto en la necesidad de advertir por escrito al Fiscal General que ha incumplido con su labor de investigar el delito. $Y$ en el caso Lafise, los jueces de cámara han advertido a la
Fiscalía que está incurriendo en responsabilidad al no investigar denuncias contra prominentes bancos del país.

A la ineficacia, el miedo y la corrupción se suma el agravante de que la Fiscalía General no dispone de los apropiados canales de queja y denuncia frente a sus propias malas actuaciones. $\mathrm{Al}$ revés de la judicatura, que tiene adecuados canales para que el ciudadano presente sus denuncias, tanto en dependencias de la Corte Suprema de Justicia como en el Consejo Nacional de la Judicatura, la Fiscalía General es un ente vertical, donde casi todas las responsabilidades terminan en el Fiscal General. Al llegar ahí, cosa que no es difícil, al ciudadano sólo le quedan, como recursos jurídi$\cos$, el antejuicio o el amparo constitucional. Medidas ambas extraordinarias, caras y de difícil gestión para el ciudadano medio de nuestro país.

No me cabe duda que frente a la situación de este cuerpo del sistema judicial, que no tiene organizada su propia formación, que no cumple con sus responsabilidades y que no dispone de un sistema confiable de deducción de responsabilidades ante una praxis mala o simplemente delictiva, se deberían tomar medidas urgentes. No sólo de una depuración, que también es necesaria y que probablemente debería comenzar por la cabeza, sino sobre todo proceder a la conformación de algún tipo de autoridad supervisora externa, que filtre la entrada a la Fiscalía General. Y que organice y supervise la institucionalización de exámenes serios como condición para ocupar el cargo, que garantice la formación permanente de los fiscales, y que posibilite la deducción de responsabilidades frente a la acción irresponsable o reñida con la ley y sus procedimientos. Sin esto, el monopolio de la acción penal se seguirá convirtiendo, y cada día más, en una burla de la justicia. E incluso aunque se dieran esas reformas, ese mismo monopolio debe encontrar alternativas que le permitan abrirse a la acción ciudadana.

La otra pieza del sistema es la policía. Órgano auxiliar de la justicia, tiene funciones no sólo de investigación y persecución del delito, sino también de prevención del mismo y educación ciudadana. De nuevo tendríamos que comenzar con alabanzas a la Policía Nacional Civil, sobre todo si la comparamos con la policías militarizadas del pasado. Mayor educación, menor prepotencia, contacto más adecuado con la población civil, serían algunas de las cualidades que mantiene la nueva poli- 
cía. Sin embargo, la cultura de la violencia, del autoritarismo y de la corupción, presentes también en nuestra sociedad, se ha ido infiltrando en este nuevo cuerpo, a veces de la mano de antiguos agentes de las policías anteriores. La depuración policial al menos de momento, parece haber puesto freno a los escándalos que hace algunos meses se sucedían casi sin interrupción. Pero algunos datos nos hacen pensar que esta especie de enjuiciamientos internos, ni han respetado algunas garantías importantes, ni han tocado ciertas raíces de corrupción que siguen amenazando al cuerpo. En

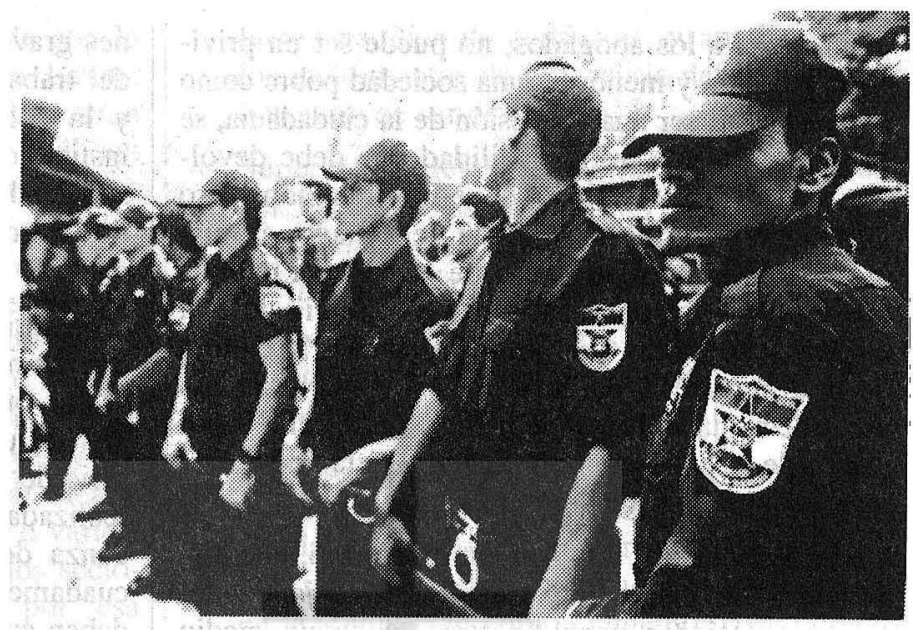
particular la protección entre los jefes, las complicidades con algunos sectores del hampa y la necesidad de ciertas aprobaciones políticas antes de proceder a determinadas investigaciones de personas o delitos. Baste para confirmar lo dicho el ejemplo del lavado de dinero. Ni la fiscalía ni la policía se atreven a investigar inversiones grandes en las que la procedencia del dinero no es clara. La investigación del narcotráfico sólo ha tocado a actores secundarios del mismo. Y tampoco se avanza en los casos en los que es necesario llegar a una autoría intelectual. El peso de las influencias, amistades y complicidades todavía es mayor que el de los esfuerzos de racionalización de la cosa pública.

La influencia de las falsas valoraciones sociales y del peso de la cultura del más fuerte, especialmente del poderoso económicamente, sigue influyendo negativamente en este cuerpo. El hecho de que se resuelvan con mucha más frecuencia, éxito y proporción los delitos de ex-

La Fiscalía General de la República, débil, poco preparada, demasiado dependiente de los nombramientos políticos y de las presiones económicas, ha adquirido, antes de tiempo, el monopolio de la acción penal [...] son demasiados los casos que han demostrado la ineficacia de este cuerpo... torsión que los delitos de

homicidio, muestra cómo la presión de los poderosos y el poco aprecio al valor vida que existen en la sociedad puede trastocar la función policial. Porque en efecto, un homicidio, y más en nuestro medio, suele dejar muchas más huellas que una extorsión. Y, ciertamente, es un delito más grave. Pero mientras la extorsión se produce generalmen- te contra los sectores pudientes, el homicidio es un delito que suele concentrarse en los sectores empobrecidos de nuestra sociedad. Sin que condenemos el éxito, necesario también para la convivencia y el desarrollo, contra la extorsión, no nos cabe duda de que entre el capital y la vida todavía la elección se inclina hacia las treinta monedas de plata.

La Procuraduría General de la República, dentro de este contexto, ha tenido una actuación discreta y relativamente eficaz. Aunque carezca todavía de un presupuesto adecuado para garantizar la defensa de quienes carecen de recursos, ha iniciado toda una serie de apoyos a la ciudadanía en campos como el de las cuotas familiares, que la ha acercado a su función y le ha ganado la confianza de muchos. Sin embargo, la débil estructuración de la defensoría pública, sigue recordándonos la necesidad de ampliar los servicios de esta institución. Se hace indispensable para un sano funcionamiento del sistema judicial pensar en modelos de defensoría pública que abarquen necesariamente a quienes ejercen privadamente la abogacía, como por ejemplo obligar por ley a cada abogado a defender un caso gratuitamente por cada diez casos pagados. El monopolio de la gestión de la justicia, dado por los 
ciudadanos a los abogados, no puede ser un privilegio gratuito, y menos en una sociedad pobre como la nuestra. Al ser una concesión de la ciudadanía, se convierte en una responsabilidad que debe devolver en servicios parte del beneficio recibido. Pero volviendo a la responsabilidad del Estado, el mismo descuido presupuestario de la defensa pública nos remite a las premisas puestas al inicio de esta conferencia, en las que nos referíamos a la cultura de la desigualdad y a la injusticia estructural. Sin una adecuada defensa pública gratuita, el 50 por ciento de la población no tiene garantía de ser tratada de un modo igual en un juicio.

Es evidente, al finalizar este recorrido, que disponemos de instituciones débiles, trabajando demasiado alejadas unas de otras, y en un medio hostil a la justicia, tal y como se entiende en una democracia. A esta debilidad de la institucionalidad se suma la todavía muy débil colaboración entre las diversas instituciones que se dedican a impulsar la justicia en el país. La policía a duras penas colabora con la fiscalía, y en ocasiones ha llegado incluso a negarle información. Los procedimientos de coordinación son con frecuencia ignorados por ambas partes, cuando no son insuficientes por falta de claridad y contenidos. Los diversos actores que promueven la justicia, aunque reconocen una cierta situación de emergencia, no toman las medidas pertinentes. Todavía es un ideal que parece lejano el pensar en que los diversos actores se reúnan para establecer prioridades, se pongan metas, analicen dificultades de coordinación, y hagan funcionar estructuras conjuntas que potencien el trabajo de todos.

El resultado es la ausencia de una política criminal de conjunto que permita enfrentar, con mayor éxito, el clima de delincuencia que vivimos. Aunque algunos podrían decir que el establecimiento de una política criminal es tarea del ejecutivo, es evidente que ésta tiene que llevarse a cabo junto con las instituciones del sector justicia. Insistir en la prevención del delito, desarrollar amplias campañas educativas, profesionalizar la investigación de tal manera que se pueda alcanzar la autoría intelectual de críme- nes graves, es indispensable. Impulsar una cultura del trabajo y la responsabilidad, del pleno empleo y la solidaridad, del adecuado funcionamiento institucional y del desarrollo y participación de la sociedad civil, debería ser tarea permanente de todos los que enfrentamos el actual clima de violencia.

Dentro de esta política es evidente que habria que someter a los funcionarios y empleados del sector público, especialmente a aquellos vinculados de una u otra manera con la justicia, a una serie de evaluaciones mucho más eficaces que las realizadas hasta el presente. La ineficacia y la tardanza deben ser controladas y sancionadas adecuadamente. Los plazos establecidos por las leyes deben cumplirse o, en la medida en que estén mal calculados, cambiarse. Lo que llamamos ignorancia inexcusable de parte de los funcionarios en el ejercicio de su trabajo debería ser causal de sanción o de despido, y no simple motivo de broma y decepción. La corrupción debe ser combatida con radicalidad. $Y$, en ese sentido, debería bastar con la existencia de indicios leves para que se iniciasen procesos de investigación. Todavía hoy demasiados empleados de la Corte Suprema de Justicia mantienen sus bufetes en activo, no son investigados en su economía y patrimonio de un modo adecuado, ni son evaluados cuando han logrado acceder a puestos relativamente altos dentro del sistema. Las instituciones con cargo de investigar deberían tener algún cuerpo especializado contra la corrupción, que permitiera poner orden en todo este tipo de corruptelas que se imponen en las oficinas públicas. Y basta poner como ejemplo al registro de la propiedad.

En él hay funcionarios que priorizan irresponsablemente un determinado orden de hipotecas, beneficiando a los bancos. Y se permitía, hasta hace poco, que bufetes privados mantuvieran, en el espacio destinado a oficinas del registro, e incluso con privilegio de prioridad en trámites, a sus propios trabajadores.

Que hay problemas es evidente, y que es necesario emprender caminos de reforma rápidos y eficaces en el sector justicia se lleva diciendo desde 
hace tiempo. Que lo legal se corresponda con lo real es una vieja aspiración en América Latina. Pero aquí nos enfrentamos a una transformación cultural. Sin participación de la sociedad civil, sin conocimiento de los derechos y responsabilidades de cada uno, sin la voluntad férrea para echarlos adelante, la reforma del sector justicia no caminará adecuadamente. En algunas ocasiones he hablado de la necesidad de mantener una especie de opción por una democracia radical. Mientras no pongamos la imaginación y el esfuerzo al servicio de una sociedad construida sobre pactos, leyes y capacidad de diálogo, los problemas seguirán siendo semejantes. Podremos encontrar un juez, o varios, honrados. Pero encontraremos en todos los sectores personas dispuestas a dejarse seducir por "esa sensación de ternura que produce el dinero" (Roberto Sosa, ibídem).

Si quisiéramos formular, muy rápidamente y para terminar estas reflexiones, la dirección que tendría que recorrer nuestra acción en favor de la justicia, propondría los siguientes:

- Organización solidaria de la sociedad civil frente al individualismo y la política del sálvese quien pueda.

- Desarrollo de una promoción incesante de los derechos económicos y sociales, y ampliación de los instrumentos de defensa de los derechos humanos a toda la sociedad.

- Promoción de instrumentos de mediación, traslado a la sociedad civil de instrumentos de so- lución pacífica de conflictos, y ampliación de los instrumentos de defensoría del consumidor o usuario de servicios.

- Supervisión del funcionamiento institucional del Estado, y especialmente de las instancias destinadas a defender la seguridad ciudadana, la legalidad y la justa aplicación de las leyes.

- Presión sobre los sectores políticos para que acepten las reglas del juego democrático y del Estado social de derecho.

- Impulso a una nueva cultura que parta de la igual dignidad de la persona humana, que defienda su autonomía, y, por ende, la oferta de una igualdad de oportunidades, y que se base en la solidaridad como elemento básico de cohesión social.

No son tareas fáciles, pero sí indispensables. El desarrollo no se logra produciendo más dinero, porque éste puede irse fácilmente hacia los bolsillos de los más sinvergüenzas. Hay que invertir en cultura, en institucionalidad, en respeto a las leyes, en legislación que garantice la igual dignidad de las personas, en mecanismos que aseguren la equidad, tanto en el trato al ciudadano como en la redistribución de una riqueza producida por todos. La responsabilidad no sólo es del Estado o de los institutos políticos, sino de todos los que conformamos la sociedad civil. $Y$ es también una responsabilidad a fin de cuentas individual, porque como personas estamos llamados a una autorrealización que no puede prescindir de la dimensión social del ser humano. 